Supporting Information for

\title{
Highly sensitive flexible piezoresistive sensor with 3D
}

\section{conductive network}

Rui Yul, Tiancheng Xia ${ }^{2}$, Bang $W u^{1}$, Jun Yuan ${ }^{2}$, Lijun $M a^{1}$, Gary J. Cheng ${ }^{* 2}$, and Feng $\operatorname{Liu}^{* 1}$

1 School of Power and Mechanical Engineering, Wuhan University, Wuhan, Hubei 430072, China;

2 Institute of Technological Sciences, Wuhan University, Wuhan, Hubei 430072, China;

3 School of Industrial Engineering, Purdue University, West Lafayette, IN 47906, USA

*Correspondence: fengliu@whu.edu.cn; Tel.: +86 18696184861; gjchen@whu.edu.cn;

Tel.: +86 18827434829 


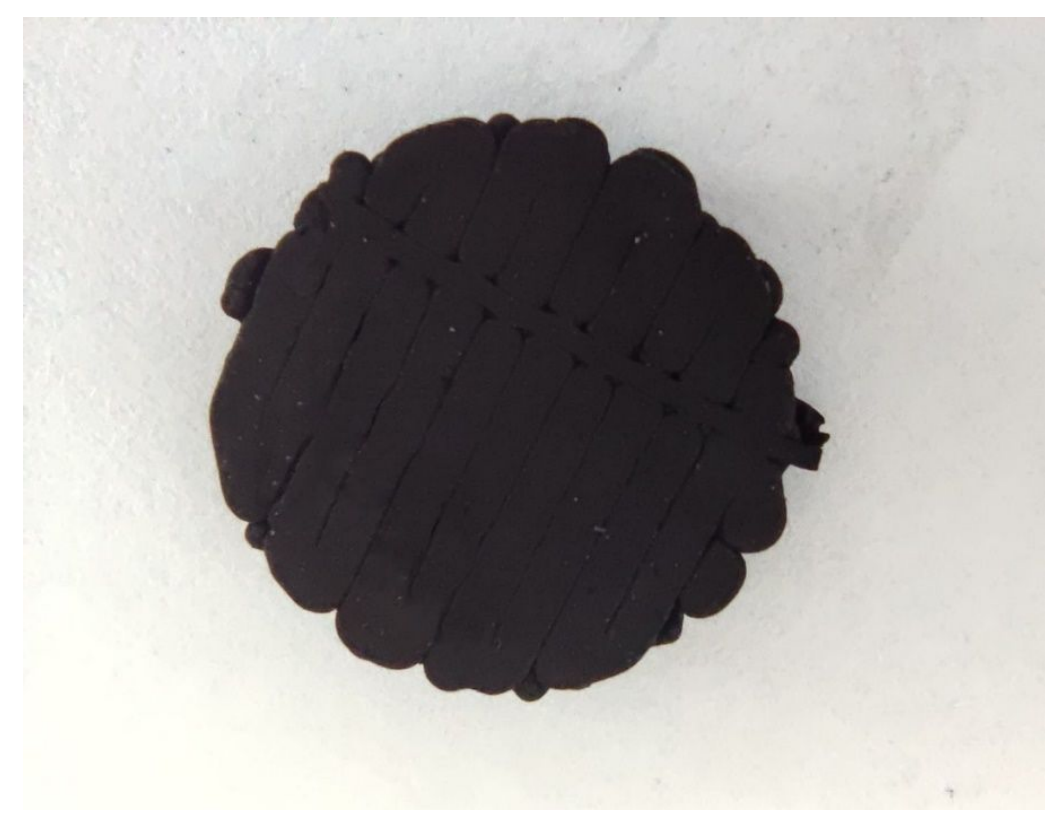

Figure S-1 Photo of sensing unit without network structure

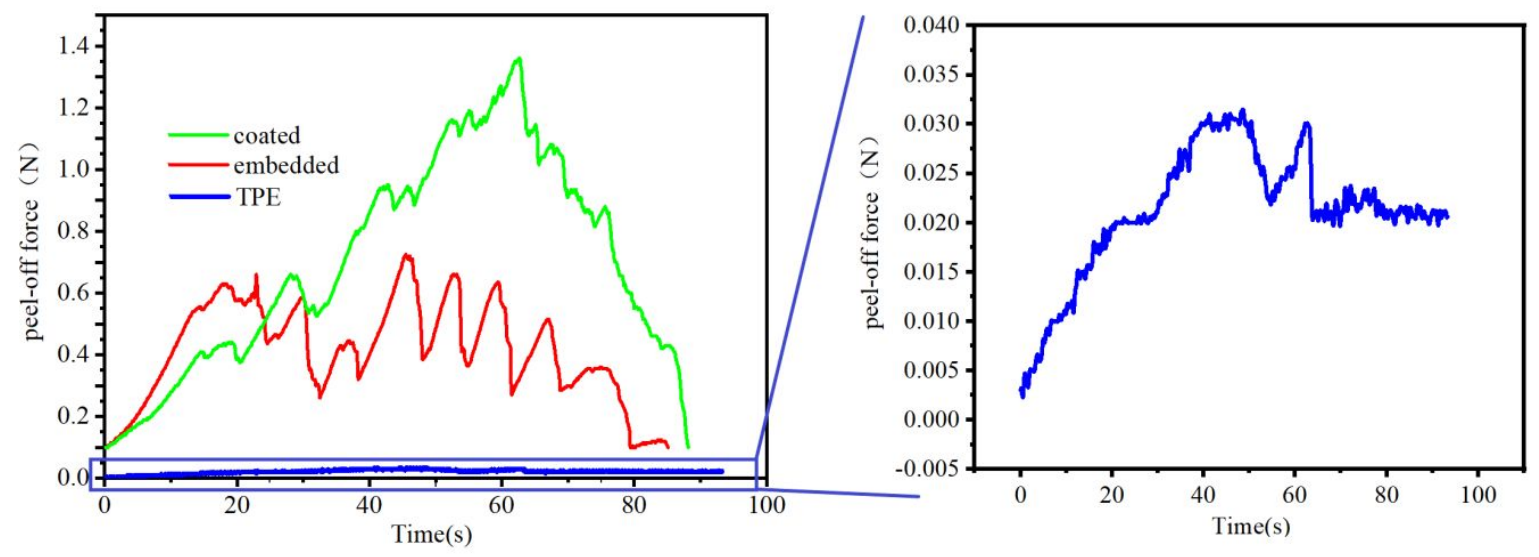

Figure S-2 Peel-off force between sensing units and test tapes 


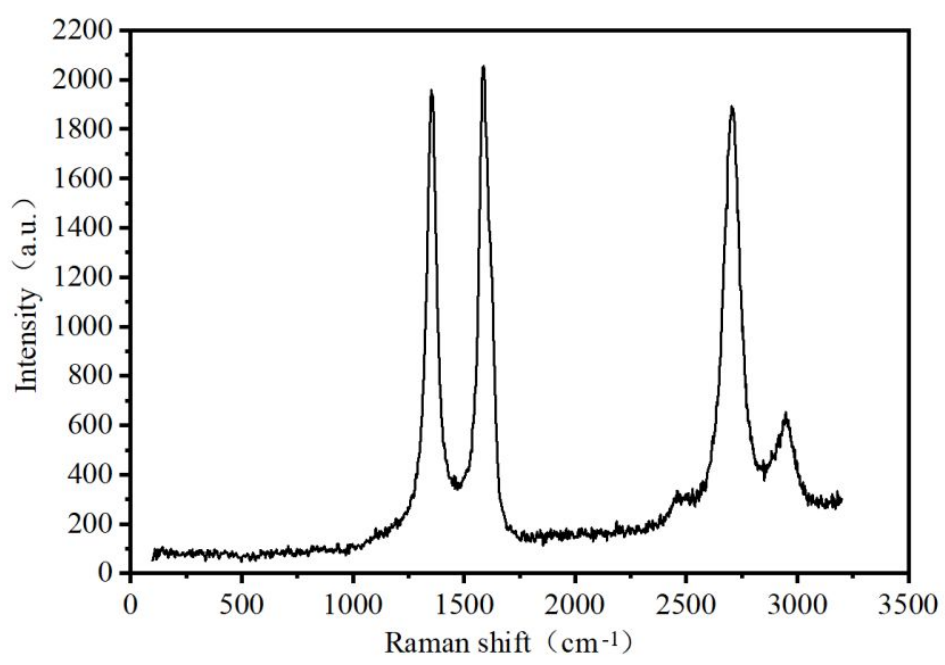

Figure S-3 Raman spectra of CNTs

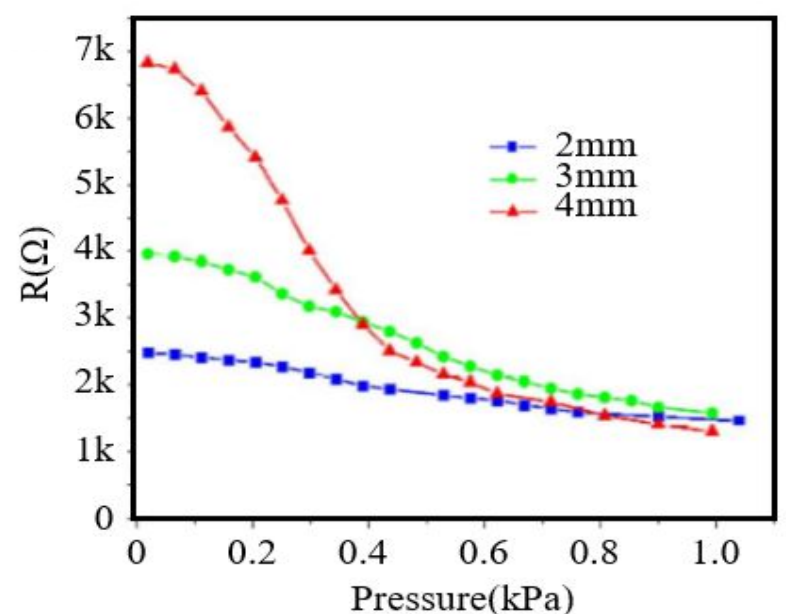

Figure S-4 Pressure-resistance curves of CNTs-embedded TPEs at different thicknesses.

Table S-1 Initial resistance of sensing units at different concentrations of CNTs suspensions

\begin{tabular}{|c|c|}
\hline Concentrations $(\mathrm{g} / \mathrm{ml})$ & Resistance in per unit length $(\Omega / \mathrm{mm})$ \\
\hline 0.01 & 62.5 \\
\hline 0.005 & 116.7 \\
\hline 0.0025 & 175.0 \\
\hline
\end{tabular}


